\title{
The NOD2 3020insC Mutation and The Risk of Familial Pancreatic Cancer?
}

\author{
Katarzyna Nej ${ }^{1, *}$, Detlef K. Bartsch ${ }^{2, *}$, Mercedes Sina-Frey ${ }^{3}$, Harald Rieder ${ }^{3}$, Stephan A. Hahn ${ }^{4}$, Jan Lubiński ${ }^{5}$ \\ IInter-University Unit of Molecular Biology, University of Szczecin and Pomeranian Medical University, Szczecin, Poland; 2Department of Surgery, Philipps-University, \\ Marburg, Germany; 3 Institute of Clinical Genetics, Philipps-University, Marburg, Germany; ${ }^{4}$ Department of Internal Medicine, Hospital Langendreer, Ruhr-University, \\ Bochum, Germany; 5 International Hereditary Cancer Center, Department of Genetics and Pathology, Szczecin, Poland
}

*These two authors contributed equally to this publication.

Notes: Katarzyna Nej is a scholarship holder from the Postgraduate School of Molecular Medicine affiliated with the Medical University of Warsaw.

Key words: NOD2, pancreatic cancer

Corresponding author: Katarzyna Nej, International Hereditary Cancer Center, Department of Genetics and Pathology, Szczecin, Poland. E-mail: kasianej@interia.pl

Submitted: 19 May 2004

Accepted: 19 July 2004

\section{Dear Sirs,}

Pancreatic cancer is an aggressive disease with a poor prognosis but despite much investigation little is known about genetic susceptibilities to this cancer [1-4].

There are several studies showing pancreatic abnormalities in patients with Crohn's disease, a chronic inflammatory condition of the digestive tract.

It has been suggested that pancreatitis could be an extrahepatic manifestation of inflammatory bowel disease, since its incidence in this disease is greater than that in the general population and in many cases no aetiological factor has been found [5]. It has been recently identified in Japan that over 6\% of Crohn's disease patients had morphological abnormalities of the pancreas [6]. There is also a notion that Crohn'sassociated pancreatitis could be a premalignant state for cystadenocarcinoma of the pancreas [7].

Recently in patients with Crohn's disease mutations in CARD15/NOD2 have been found. NOD2 encodes a protein involved in bacterial recognition by monocytes.

The NOD2 gene is localized to chromosome 16 and is comprised of 12 exons that encode a protein of 1040 amino acids [8]. Several mutations have been identified in the NOD2 gene, which appear with a significantly higher frequency in patients with Crohn's disease. One such mutation (3020insC) is believed to be clearly causative because it is the only common variant which results in a prematurely truncated protein predicted to reduce its functional efficiency. It has been recognized recently that the presence of this particular NOD2 mutation increases the risk of developing colorectal cancer characterized by a later average age of disease diagnosis [9]. Since the risk of cancers at various sites has been characteristic among patients with Crohn's disease, it was considered justified to study the relationship between the $3020 \mathrm{ins} C$ mutation and other cancer risks. Here, we report the analyses of the 3020insC mutation in the NOD2 gene in patients with pancreatic cancer.

Initially, we have examined the frequency of the 3020ins C mutation in a series of 158 patients divided into 3 groups:

1. 127 consecutive pancreatic cancers;

2. 4 familial cases - pancreatic cancer patients from families with at least two pancreatic cancers on the one side of the family;

3. 27 healthy children of pancreatic cancer patients from families with at least two pancreatic cancer cases where DNA samples from affected individuals were not available.

Individuals from the last group were younger than 46 years. In the consecutive group peripheral blood samples were available from 58 cases. DNA from the 


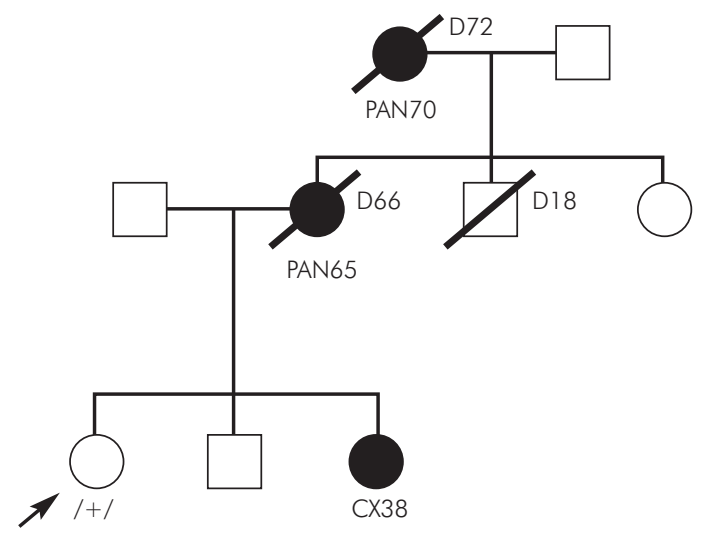

Fig. 1. Pedigree of the family with 3020insC mutation

remaining patients was isolated from paraffin embedded tissues. In all familial cases and the group of healthy children DNA samples were obtained from the peripheral blood lymphocytes.

The control group consisted of 300 consecutive newborns from the clinical hospitals of Szczecin. DNA samples were obtained from umbilical cord blood.

The method described by Ogura et al [8] was used to identify the 3020 ins $C$ mutation. The sequence of the PCR products was confirmed by DNA sequencing.

The frequency of the 3020ins C mutation in the control group was $7 \%$. In the group of consecutive cases six C-insertion mutations were identified (4.7\%). In the four independent familial pancreatic cancer patients no mutation was found, but four changes $(14.8 \% ; 4 / 27)$ were detected in the group of healthy children of pancreatic cancer patients derived from families with aggregations of these tumours (Fig. 1).

Since our results indicated that there was an increased frequency of the 3020ins $\mathrm{C}$ mutation in familial pancreatic cancer cases we decided to enlarge this group. 30 additional histologically confirmed familial pancreatic cancer patients of independent families from the German National Case Collection for Familial Pancreatic Cancer of the Deutsche Krebshilfe (FaPaCa) were included in this study [10]. The frequency of the mutant allele in this group did not confirm our initial result since only two changes were found $(6.7 \% ; 2 / 30)$.

However, even if Polish and German familial cases are combined it is still an open question whether 3020ins C is related to a predisposition to familial pancreatic cancer. Further investigations on a larger number of cases are needed.

In summary we cannot conclude that NOD2 is not involved in familial pancreatic cancer but it appears not to be associated with sporadic cases of disease.

\section{References}

1. Manu M, Buckels J and Bramhall S. Molecular technology and pancreatic cancer. Br J Surg 2000; 87 (7): 840-853.

2. de Vos tot Nederveen Cappel WH, Lagendijk MA, Lamers CB, Morreau $\mathrm{H}$ and Vasen HF. Surveillance for familial pancreatic cancer. Scand J Gastroenterol Suppl 2003; (239): 94-99.

3. Goggins M, Kern SE, Offerhaus JA and Hruban RH. Progress in cancer genetics: lessons from pancreatic cancer. Ann Oncol 1999; 10 Suppl. 4: 4-8.

4. Moore PS, Beghelli S, Zamboni G and Scarpa A. Genetic abnormalities in pancreatic cancer. Mol Cancer 2003; 2 (1): 7.

5. Anton MD, Ortiz I, Lopez A, Delgado F, Barrachina M and Moreno E. Chronic pancreatitis as the initial presentation of Crohn's disease. Gastroenterol Hepatol 2003; 26 (5): 300-302.

6. Oishi Y, Yao T, Matsui T, Ueki T, Sakurai T and Sakaguchi S. Abnormal pancreatic imaging in Crohn's disease: prevalence and clinical features. J Gastroenterol 2004; 39 (1): 26-33.

7. Gotian A and Katz S. Pancreatitis associated with Crohn's disease: a premalignant state for cystadenocarcinoma of pancreas? Am J Gastroenterol 1999; 94 (8): 2301-2302.

8. Ogura Y, Bonen DK, Inohara N, Nicolae DL, Chen FF, Ramos R, Britton H, Moran T, Karaliuskas R, Duerr RH, Achkar JP, Brant SR, Bayless TM, Kirschner BS, Hanauer SB, Nunez G and Cho $\mathrm{JH}$. A frameshift mutation in NOD2 associated with susceptibility to Crohn's disease. Nature 2001; 411 (6837): 603-606.

9. Kurzawski G, Suchy J, Kladny J, Grabowska E, Mierzejewski M, Jakubowska A, Debniak T, Cybulski C, Kowalska E, Szych Z, Domagala W, Scott RJ and Lubinski J. The NOD2 3020insC mutation and the risk of colorectal cancer. Cancer Res 2004; 64 (5): 1604-1606.

10. Bartsch DK, Sina-Frey M, Ziegler A, Hahn SA, Przypadlo E, Kress R, Gerdes B and Rieder H. Update of familial pancreatic cancer in Germany. Pancreatology 2001; 1 (5): 510-516. 